\title{
O arquivo do inventário dos marginais da diferença na pesquisa curricular
}

\section{brasileira}

\author{
The inventory archive of the marginals of the difference in the brazilian curricular research \\ El Archivo del inventario de los marginales de la diferencia en la investigación curricular brasileña
}

Recebido: 07/01/2021 | Revisado: 08/01/2021 | Aceito: 19/02/2021 | Publicado: 27/02/2021

\author{
Daniela Carolina Ernst \\ ORCID: https://orcid.org/0000-0002-6462-2867 \\ Universidade Federal da Fronteira Sul, Brasil \\ E-mail: daniela.ernst@ufrgs.br \\ Deniz Alcione Nicolay \\ ORCID: https://orcid.org/0000-0003-4218-3573 \\ Universidade Federal da Fronteira Sul, Brasil \\ E-mail: deniz.nicolay@uffs.edu.br
}

\begin{abstract}
Resumo
Há mais de três décadas, somos testemunhas da contaminação da perspectiva da Filosofia da Diferença, encabeçada por Deleuze \& Guattari, assim como a dos pensadores reconhecidos como os malditos nas pesquisas do campo da psicanálise, da antropologia, dos estudos de gênero, da educação e do campo curricular. Nesse sentido, o movimento desta escrita acontece frente à necessidade de se registrar essa memória formativa, assim como suas rizomáticas linhas de conexão, pois entende-se que ainda se estabelecem no cosmos em um estado espectral. Ao fazer esse movimento, optamos pela metodologia do arquivo, tal qual estabelecida por Derrida (2001), no sentido de problematizar as múltiplas possibilidades de se conhecer tais encontros.
\end{abstract}

Palavras-chave: Filosofia da diferença; Currículo; Inventário; Educação.

\begin{abstract}
For over three decades, we have witnessed the perspective of the Philosophy of Difference contamination, led by Deleuze \& Guattari, as well as that of think ${ }^{8}$ ers recognized as the damned in research in the field of psychoanalysis, anthropology, gender studies, education and the curricular field. In this sense, the movement of this writing happens due to the need to register this formative memory, as well as its rhizomatic lines of connection, as it is understood that these are still established in the cosmos in a spectral state. In making this movement, we opted for the archive methodology as established by Derrida, in order to problematize the multiple possibilities of knowing these encounters. Keywords: Philosophy of Difference; Curriculum; Inventory, Education.

\section{Resumen}

Durante más de tres décadas, hemos sido testigos de la perspectiva de la contaminación de la Filosofía de la Diferencia, liderada por Deleuze \& Guattari, así como la de pensadores reconocidos como condenados en investigaciones en el campo del psicoanálisis, antropología, estudios de género, educación y el campo curricular. En este sentido, el movimiento de esta escritura ocurre por la necesidad de registrar esta memoria formativa, así como sus líneas rizomáticas de conexión, ya que se entiende que estas aún se encuentran establecidas en el cosmos en un estado espectral. $\mathrm{Al}$ realizar este movimiento, optamos por la metodología de archivo establecida por Derrida, con el fin de problematizar las múltiples posibilidades de conocer estos encuentros.
\end{abstract}

Palabras clave: Filosofía de la diferencia; Plan de estudios; Inventario, Educación.

\section{Introdução - Situando a Questão}

O lugar em que é posto o pensamento teórico na tradição colonial, constitui-se historicamente por diferentes premissas, como: ser racionalizante - "Penso, Logo Existo" -, reconhecendo o sujeito racional no limite do conhecimento, ou seja, a razão sobre algo, como se essa tivesse mais valor do que o algo em questão; esse tipo de pensamento também está ligado ao capitalismo expropriatório porque entende a natureza como insumo e estabelece o homem como senhor de todas as coisas, não o enxergando como parte do todo cosmológico ou aceita a sua parcela animal; liga-se, também, a modelos hierarquizantes na medida em que defende que existam espaços que podem ser ocupados por mulheres, por diferentes tipos de pessoas e que esses limites impostos 
não podem ser ultrapassados; da mesma forma, relaciona-se ao entendimento que se tem sobre raça, quando defende que existam raças superiores, como se algumas etnias, com diferentes fenótipos, fossem superiores biológica e cognitivamente, ou que existam conhecimentos, estes atrelados a culturas que sejam mais importantes do que outras, silenciando, assim, ao longo do tempo, inúmeras vozes.

Nesse sentido, fomos sendo atravessados por tal tipo de formatação e guiados ao entendimento, coletiva ou individualizadamente, desse modelo de pensamento, tendo-o como um modelo único e absoluto, de superioridade, que opera através da hierarquização e da segmentarização das coisas, das pessoas, das subjetividades.

O produto, então, feitas todas as ressalvas e todas as exceções, é o homem branco, cristão, patriarcal, machista, heteronormativo, homofóbico e obcecado por muitas coisas, entre elas, pela pulsão anal e falocêntrica. Segundo Lacan ${ }^{1}$ (1999), o que caracteriza o sujeito obsessivo é a sua capacidade de pensar, mas com a característica de que ele pensa para si mesmo e para anular o desejo do outro.

Contudo, se o obsessivo através do medo ou do fascínio se dedica a menosprezar, atacar e, assim, destruir o desejo do Outro, tende a desvalorizar e depreciar aquilo que é seu próprio desejo, mais íntimo e reprimido. O certo é que a cultura ocidental, ao longo da sua constituição, privilegiou alguns modos de pensar, de viver, de se relacionar, de produzir ciência, de perceber o ensino, a educação e os currículos em detrimento e desqualificação de tudo que não for eurocêntrico e que não faz parte da matriz judaico-cristã.

O que precisa ficar entendido, ao menos até aqui, é que o pensamento teórico não é nada além de outras formas de expressão do pensamento. Esses primeiros parágrafos são imprescindíveis para o entendimento do que vem a seguir. Esse é o entendimento, mesmo que superficial, da importância da perspectiva da multiplicidade operacionalizada por Deleuze e Guattari (1971) como possibilidade de resistência a essa acepção de pensamento.

Se optamos por embarcar no esforço teórico de construir um arquivo-inventário da contaminação dos marginais da diferença na pesquisa curricular brasileira e ousamos pensar neles sob os signos do nosso tempo e espaço, fazemo-lo e aproximamo-nos desses autores porque eles são brancos, europeus e buscavam, em conjunto ou separadamente, desvencilhar-se de seu triste destino euro logo falocêntrico, e lograram fazê-lo teórica e existencialmente, na medida que ambos viveram essas posições, cada um à sua maneira ao longo de suas vidas.

\section{Metodologia}

Mesmo que a princípio o inventário possa remeter a uma aparente necessidade de sistematização, recurso adotado por qualquer pesquisador, a maneira como se organiza o material recuperado, a escolha ou não de alguma estratégia, explicitam a nossa própria compreensão sobre o conhecimento levantado a respeito do tema que investigamos. Neste sentido, a escrita deste artigo não deixa de ser um resgate temporal, com requintes de inventário da contaminação viral do pensamento da diferença no campo curricular através dos movimentos - arquivista e inventariante -, pois busca catalogar e, assim, registrar o patrimônio intelectual deixado por Deleuze e Guattari nas pesquisas curriculares brasileiras.

\footnotetext{
${ }^{1}$ Para Lacan: "O corpo, o corpo idealizado, reclama um sacrifício corporal. Esse é um ponto importantíssimo para compreender [...] a estrutura do obsessivo" (Lacan, 1968-1969/2008, p. 359).
} 


\section{O Arquivo: de "Lugar de Memória" a "Lugar para a História"}

Trata-se de uma pesquisa que percorre fluxos que anseiam “[...] por Vida (Biografia) e por Obra (Bibliografia). Só que, em vez de Vida e Obra tomadas em separado, ou uma derivada e mesmo causa da outra, trata de Vidarbo [...]” (Corazza, 2010, p. 86).

Isso não deixa de ser: “ um movimento para fora, voltado para uma comunhão com os outros” (Barone; Eisner, 2012, p. 64). Esse movimento tenciona contribuir como uma prática de emancipação, tanto para os pesquisadores quanto para os leitores/espectadores, e torna-los possíveis pelos conhecimentos gerados, para atualizá-los a partir do nosso olhar,carregado de subjetividades, experiências, afetos, onde a escrita percorre linhas que permeiam a vida enquanto palavra eternizada. Nossos desejos e afetos, precisam ser entendidos como variante nesse processo poético que se estabelece entre o pesquisar e o escrever. Precisa ser assim, porque “[...] o espírito humano enfrenta dificuldades para pensar o informe. Daí surge a necessidade [...] de uma Educação ou pedagogia dos sentidos, associando a vivência dos limites formais com a criação artistadora" (Corazza, 2010b, p. 2).

Contudo, após o advento da psicanálise, não podemos nos remeter ao conceito de arquivo com a mesma visão simplista e ingênua, uma vez que o arquivo pode promover um movimento de fora pra dentro, mas também pode, de acordo com Derrida ${ }^{2}$ (1995), encarcerar a história, ou seja, o arquivo pode ser considerado como textos que sofreram inúmeras revisões decorrentes de repressões, negações, apagamentos e censuras, ou seja, a repressão está permanentemente possibilitando o mal de arquivo, o esquecimento, o apagamento da memória. Essa, entretanto, não é a ressonância da nossa escrita e pela qual gostaríamos que este texto fosse lido. Nossa intenção é o oposto disso, entendemos o arquivo como local de memória e de história, local de afetos e afectos.

O movimento de inventariar o pensamento da filosofia da diferença no campo curricular é, portanto, uma estratégia que se constitui a partir do entendimento de que essa memória precisa ser inventariada e preservada. Cabendo a cada pesquisador, estabelecer suas próprias regras e estratégias de pesquisa para acessar o plano que enseja articular, agenciar, conectar a partir dessa diversidade.

Dessa maneira, entendemos que toda metodologia guiada pela perspectiva da multiplicidade precisa ser entendida como um trabalho em rede, como uma obra de arte que se realiza através do estudo das malhas constitutivas que se estabelecem entre o tempo e o espaço dos acontecimentos, entre os registros que vão sendo encontrados, entre as subjetividades envolvidas, e que busca para além dos dados e estatísticas, o vir a ser do objeto pesquisado, a memória do tempo vivido, de acordo com Roland Barthes (2012, p. 62), o texto é um “[...] espaço de dimensões múltiplas, onde se casam e se contestam escrituras variadas, das quais nenhuma é original".

Aqui, dados, afetos, histórias e pessoas, ou seja, o grupo implicado na pesquisa, e mais do que um conjunto de pessoas e de coisas reunidas que se misturam no sentido de dar vida à atividade humana, feita para outros seres humanos que é a pesquisa do campo curricular brasileiro. A metodologia passa a constituir-se como um instrumento de custódia do objeto pesquisado, conferindo ao pesquisador a responsabilidade de preservação das múltiplas histórias que também são os dados. Esse movimento liga-se diretamente a Derrida, em sua obra, Mal de Arquivo: Uma Impressão Freudiana ${ }^{3}$ (2001). No texto, é possível identificar

\footnotetext{
2 Parte do entendimento de Derrida, a partir dos escritos de Freud acerca da memória e da escrita, contidas no livro : Jacques Derrida - "Freud e a cena da escritura" in "A escritura e a diferença" - p. 179-227 - Editora Perspectiva - 2a edição - São Paulo - 1995.

3 "Mal de Arquivo - Uma impressão freudiana" é uma conferência de Derrida pronunciada em Londres, no dia 5 de junho de 1994, no colóquio internacional "Memória, a questão dos arquivos", organizado por iniciativa de René Major e Elizabeth Roudinesco e patrocinada pela Sociedade Internacional de História da Psiquiatria e da Psicanálise, do Museu Freud e do Instituto de Arte Courtauld. No deslocamento de Derrida para a experiência de construção dessa metodologia, utilizamos como base teórica os livros : Jacques Derrida - "Freud e a cena da escritura" in "A escritura e a diferença" - p. 179-227 - Editora Perspectiva - 2a edição - São Paulo - 1995 Jacques Derrida - "Mal de Arquivo - Uma impressão freudiana" - Editora Relume Dumará - Rio de Janeiro - 2001
} 
uma tentativa de acepção do que seria um arquivo, existe uma desconstrução do historicamente estabelecido da imagem clássica do que seria um arquivo.

Derrida inspira nosso movimento arquivístico e inventariante, quando questiona o pensamento logocêntrico, fazendo funcionar a sua estratégia operatória, a "desconstrução", ou seja, o esquartejamento e o ajuntamento das partes de um texto, sempre no interior dele mesmo, evidenciando que os princípios envolvidos na forma, ou formatação do texto, podem tornar-se sua ruína.

Dessa maneira, nosso inventário arquivístico, também, aproxima-se do entendimento de Pierre Nora e Peter Burke, no sentido de ter o arquivo como experiência subjetiva, que vai além da preservação de documentos ou da descrição de fatos históricos, mas que entende o arquivo como um lugar de memória, no sentido lato do termo: "um lugar material, simbólico e funcional" (Nora, 1993, p. 21), ou seja, de que na pesquisa "[...] tudo se compõe, se combina, se substitui, se compensa, se mistura e se desmistura, e isso é o Espírito" (Valéry, 2016, p. 32).

Partindo do entendimento do acima exposto, estabelece-se o que a princípio pareceria uma "desordem organizada", do qual nasceria o nosso arquivo. A documentação a seguir descrita e custodiada neste trabalho reflete bem aquilo que ele quer representar: uma memória sobre a história da pesquisa curricular brasileira pelo viés da filosofia da multiplicidade.

Nesse tipo de empreendimento investigativo, quanto mais mergulhamos no material analisado, mais experimentamos objeto e, assim, somos agenciados pelo objeto da pesquisa. Fomos, então, guiados por essa percepção de preservação e de entendimento dos fatos, que se estabelece a partir das conexões que possam ter sido construídas pelo pesquisador quando ainda na leitura dos documentos.

Resta a pergunta: De que maneira construímos o arquivo que compõe o plano de imanência ${ }^{4}$ desta pesquisa? Dois livros serviram como base para as análises das datas referentes aos diferentes encontros de Deleuze e Guattari e deles com outros pensadores. Essas obras são: Gilles Deleuze \& Felix Guattari Biografia Cruzada (2010), escrita pelo historiador Francois Dosse e publicada no Brasil, em 2010, pela editora Artmed de Porto Alegre; e o livro do Deleuze e a Educação, do professor, filósofo e pesquisdor em educaçãoo da UNICAMP, Sílvio Gallo, obra está que faz parte da coleção Pensadores \& Educação, lançada pela editora Autêntica, em 2007.

A partir da leitura dessas obras, começamos o trabalho de construção dos nossos arquivos, compostos de fichas que visavam catalogar os conceitos que se estabeleciam nos textos, além de diários de pesquisa, mapas, rascunhos, anotações sobre os livros e artigos lidos e analisados e que fazem parte desta pesquisa.

Durante esse trajeto, percebemos o paciente zero da perspectiva, a célula contaminante de todo um campo do saber e do pensar: Suely Rolnik. A partir dela, todo o material foi sendo descoberto, as primeiras publicações, as revistas, as palestras, as entrevistas de Deleuze e Guattari, a organização do material impresso em português, as entrevistas da respectiva professora explicando a perspectiva e seus conceitos são a base de toda essa escrita.

Em nossa pesquisa-arquivo, optamos por utilizar diversos nomes para a filosofia, entre eles podemos citar: filosofia da diferença, filosofia da multiplicidade, filosofia da imanência, biogeofilosofia e geofilosofia. Por consecutivas vezes, alguns desses descritores foram relacionados a outros pensadores, tais como: Foucault e Derrida. Contudo, optamos pelo movimento de manutenção dos autores supracitados. Essa opção se deve ao teor investigativo da pesquisa e, também, no sentido de evitar a repetição excessiva de nomes e de termos.

\footnotetext{
${ }^{4}$ Nas palavras de Deleuze: "O plano de imanência é ao mesmo tempo o que deve ser pensado, e o que não pode ser pensado. Ele seria o nãopensado no pensamento. É a base de todos os planos, imanente a cada plano pensável que não chega a pensá-lo. ("O Que É a Filosofia?", Ed. 34, pág. 51).
} 
Delimitadas as justificativas dos próximos movimentos, partimos, então, para os diferentes e múltiplos encontros que se estabeleceram ao longo do tempo, entre Deleuze e Guattari, e as multiplicidades de diferentes autores e pesquisadores que se juntaram a essa perspectiva teórica de abertura do pensar.

\section{Os Dois, ou Entre os Dois...}

Antes de documentar o encontro entre Deleuze e Guattari, é de fundamental importância fazer o exercício de análise de contextos mais amplos, da temporalidade e da historicidade profunda e real, marcadas que foram deixadas em diferentes momentos, que compunham as interações estabelecidas entre a vida que se vivia, o mundo que se apresentava as relações que se experienciam e se estabeleciam entre a vida que se queria viver, no mundo se queria construir.

Maio de 68 precisa ser compreendido enquanto movimento de renovação de valores, acompanhados pela potencial da pulsão e dos fluxos de linhas de transformação, demandas por reconhecimento, movimento estudantil e operário, revolução sexual, cultura pop ${ }^{5}$, movimento global de organização das minorias, juventude que se alia à classe operária e organiza uma das maiores greves da história, com a participação de 9 milhões de pessoas.

\section{A Partir de Maio de 1968}

Esse ciclo absolutamente revolucionário faz com que Deleuze e outros pensadores, como Sartre e Foucault, também participem das manifestações na tentativa de proteger seus alunos contra violência policial. Concomitantemente, Guattari participa ativamente da organização dos protestos, na articulação e no planejamento de algumas ações revolucionárias ${ }^{6}$ que aconteceram em Maio de 68, dentre elas a ocupação do Instituto Pedagógico Nacional e do Théâtre de L'Odéon (Dosse, 2010, p. 148). Contudo, até aquelas manifestações, "nada predestina seus dois mundos a se encontrar" (Dosse, 2010, p. 13).

Deleuze tinha 44 anos em 1968 e já tinha seu trajeto acadêmico reconhecido como professor e filósofo. Havia publicado boa parte de sua obra e era respeitado no campo da filosofia. Para Deleuze interessava a psicanálise, em especial, as análises de Freud acerca dos processos capitalistas a partir da revolução industrial. A psicanálise, a partir da leitura dos processos capitalistas, iria aproximá-lo de Guattari.

Pelas limitações impostas pela doença ${ }^{7}$, em Deleuze movimentos eram lentos, sua fala pausada e pensada, e, apesar de ter uma alma agitada, era visto como uma pessoa tranquila. Em entrevista concedida a Magazine I.ittéraire, os entrevistadores arriscaram-se a definir algumas das suas particularidades: "viaja pouco, jamais aderiu ao Partido Comunista, jamais foi fenomenólogo nem heideggeriano, não renunciou a Marx, não repudiou Maio de 68”. Mas do que gostava Deleuze?

De acordo com Dosse (2010) e por testemunho do próprio Deleuze, ele gostava de ser professor, ofício que exerceu com paixão e, por isso, acabou sendo reconhecido por seus alunos. Empenhava muito esforço à atividade docente, pois reconhecia a importância da preparação minuciosa das suas aulas. Em entrevista a Raymond Bellour e François Ewald, em 1988, traduzida e publicada em 1992 pela Revista Brasileira Conversações, quando questionado a falar a respeito da sua vida enquanto docente, afirmou o seguinte: “As aulas foram uma parte da minha vida, eu as dei com paixão" (Deleuze, 1992, p. 173-174).

Guattari é, em diferentes sentidos, o oposto de Deleuze. Desde muito jovem, envolve-se com a militância de esquerda e com a direção dos albergues da juventude, onde conheceu Fernand Oury, irmão mais velho de Jean Oury - com quem mais

\footnotetext{
${ }^{5}$ No Brasil, o movimento de contracultura abriu campos para o cinema novo, tropicalismo, arte conceitual deslocando-a dos museus e galerias para outros espaços, esses mais democráticos (ruas, avenidas, muros, etc).

${ }^{6}$ Guattari levava médicos, enfermeiros, profissionais que trabalhavam em La Borde assim como seus pacientes para as manifestações.

7 Deleuze, sofria de problemas respiratórios, desde tenra infância, e de uma patologia que causava dores nas pontas dos dedos. Para protegerse, deixava as unhas compridas.
} 
tarde trabalharia em La Borde. Por indicação do irmão, torna-se estudante de farmácia, abandonando-a pela filosofia em Sorbonne. Durante seus estudos, envolveu-se com a psicanálise e participou do grupo de estudo de Lacan ${ }^{8}$, sendo o único não psiquiatra a ser convidado para as palestras e discussões.

Durante esse tempo, foi pupilo e paciente de Lacan,“(...) mas à maneira de um 'filho’ que já sabe que não há conciliação possível” (Deleuze, 1992, p.180), abandonando-o para dedicar-se à pulsão da vida que acontecia ao redor. Assim, guiou seus esforços para o desenvolvimento da psicoterapia institucional com o amigo Jean Oury, na lendária clínica La Borde.

Em La Borde, desempenhou função de diretor por muitos anos, revolucionando a administração ${ }^{9}$ da instituição na cogestão da clínica com os pacientes e funcionários, e na criação de modelos de reinserção dos pacientes nas atividades diárias, dando-lhes liberdade de circulação, tornando-os parte da instituição ao delegar-lhes tarefas.

De espirito inquieto e hiperativo, Guattari dedica grande parte de sua vida a militância de esquerda e de luta antimanicomial, o que o leva a criar, em 1967, o Centre d'études de recherches et de formation institutionnelles, uma organização composta por intelectuais de esquerda, que tinha como propósito pensar as ciências humanas a partir do olhar da transdisciplinaridade. O encontro aconteceu graças à mediação de um amigo-intercessor em comum, Jean ${ }^{10}$ Pierre Muyard $^{11}$, com quem Guattari trabalhava na clínica La Borde ${ }^{12}$. É necessário destacar o papel que a amizade como um intercessor irá ocupar em todas as relações que irão se estabelecer. Elas tornam-se virtualidades importantes nessa conjunção de imanência DeleuzeGuattariana (GALLO, 2007). A amizade é um dos mais potentes intercessores no sentido de trocas, de agenciamentos e de criação.

Em junho de 1969 Muyard, apresentou Guattari e Deleuze. O encontro orquestrado por Muyard aconteceu em SaintLéonard-de-la-Noblat, em Limousin. É descrito por Muyard como uma sedução mútua e imediata entre os dois pensadores. Após o primeiro contato estabelecido entre os dois, Deleuze, aproveitou para aprofundar sua contestação ao lacanismo e seus estudos freudianos, e iniciar seu período de grande produção textual. Guattari entrou em cena. A partir dessa aproximação, os dois começaram a trocar correspondências sobre a questão da psicanálise, nas quais encontraram um objeto comum. A mesma crítica que Marx havia feito ao capitalismo ${ }^{13}$, foi feita por Deleuze e Guattari à psicanálise.

De acordo com o biógrafo Fraçois Dosse, essa combinação Deleuze-Guattariana acaba produzindo o que ele convencionou chamar de "motor em dois tempos" (DOSSE, 2010, p. 20). Cada um a seu tempo, respeitando as especificidades

\footnotetext{
8 Félix participou da criação da Escola Freudiana de Paris, juntamente com Lacan, em 1964.

${ }^{9}$ Cria experiências, experimentações, entre elas a terapia em grupo e o método de Grade, que divide as tarefas administrativas da Clínica entre pacientes, trabalhadores e médicos por escala.

${ }^{10}$ Muyard vai estudar medicina em Lyon no final dos anos 1950. Militante, torna-se presidente, em 1960, da Union Nationale des Étudiants de France (UNEF). Paralelamente à especialização em psiquiatria, faz cursos em sociologia na Faculdade de Letras de Lyon. Seu encontro com Félix ocorreu em 1964, por ocasião de um seminário que se realizou em Poissy. Em 1966, foi convidado a clinicar em La Borde, onde permaneceu até 1972. Quando era estudante em Lyon.. Em 1967, ficou entusiasmado com a publicação de Sacher-Masoch e se aproximou de Deleuze, com quem manteve um canal de diálogo sobre o mundo dos psicóticos.

${ }^{11}$ Em uma entrevista concedida a François Dosse, Jean-Pierre Muyard lembrou de seu encontro com Félix Guattari em um seminário da oposição de esquerda que se realizou na cidade de Poissy em 1964.

${ }^{12}$ La Borde - Clínica fundada (1953) por Jean Oury, que convida para a direção administrativa Félix Guattari, em 1956. La Borde foi um campo experimental importantíssimo para a psicanálise e o desenvolvimento da psicoterapia. Dentro do seu quadro de trabalhadores/visitantes ilustres podemos destacar: Paul Eluard, Frantz Fanon, e Georges Canguilhem.

${ }^{13}$ Assim como Marx criticava o capitalismo por defender que a teorização fortalecia o processo de exploração e dominação, assim o fizeram Deleuze e Guattari em relação à psicanálise, o que os levou a produzir o livro O Anti- Édipo capitalismo e esquizofrenia.
} 
do outro através de práticas de escrita, de encontros e atravessamentos intensos, resulta na publicação em 1972 do livro: $O$ AntiÉdipo (1972) ${ }^{14}$, seguido por Kafka, por uma literatura menor (1975), Mil Platôs (1980) e O que é filosofia? (1991) ${ }^{15}$.

Somam-se a essa contagem, inúmeros escritos individuais ou com colaboração com outros parceiros e intercessores filosóficos, dentre os quais, merece destaque a parceria estabelecida entre Deleuze com a jornalista Claire Parnet, com quem Deleuze escreve Diálogos (1977) e com quem acorda gravar a entrevista Abecedário (1988-1991). Ao conceder a entrevista, faz duas exigências, tendo em vista sua debilidade física e já muito fragilizado emocionalmente pela doença, duas cláusulas tácitas: 1) ele precisaria refletir sobre o tema, para ele era inconcebível dar uma opinião sobre algo sem ponderar sobre a questão primeiro; e 2) a entrevista só poderia ser exibida após a morte, o que aconteceria pouco tempo depois, em 1995. Entre as amizades filosóficas estabelecidas por Guattari, a que merece destaque é a que ele estabelece com Suely Rolnik ${ }^{16}$.

Ela, já formada em Ciências Sociais pela Universidade de São Paulo - USP, exilou-se na França durante a ditadura militar, onde deu continuidade aos seus estudos na mesma Universidade onde Deleuze dava aula. Estudou Ciências Sociais, Filosofia e, também, fez mestrado e DESS em Ciências Humanas Clínicas (revalidado no Brasil como Psicologia) na Universidade Paris VII (Diderot). Deleuze a apresenta a Guattari, durante algum tempo, ela foi paciente de Guattari e, dessa maneira, frequentava a clínica La Borde, estabelecendo uma amizade que perdurará até a morte de Guattari, em 1992.

Voltando ao Brasil, graças à Lei da Anistia, em 1979, tornou-se professora de Psicologia Social na Pontifica Universidade Católica de São Paulo (PUC-SP). No mesmo ano, criou o Núcleo de Estudos da Subjetividade, no Programa de Pós-Graduação em Psicologia Clínica da PUC-SP, grupo ativo e muito produtivo até os dias de hoje.

Em conjunto, Guattari e Rolnik escreveram inúmeros artigos e viajaram pelo Brasil em função das palestras de Guattari. O resultado das incursões em terras brasileiras, materializa-se no livro que inaugura a prespectiva da Multiplicidade ou da Diferenca no Brasil: Micropolítica: Cartografias do Desejo $(1986)^{17}$. Nele, além de textos escritos pelos dois, encontramos o relato de uma série de debates realizados entre Rolnik-Guattari e os mais diversos personagens que estavam envolvidos nas instituições e movimentos sociais. Essa obra foi publicada em diversos países e reeditada em 2013 pela Editora Vozes.

Foi através da professora Suely Rolnik que a cartografia se estabeleceu como metodologia na pesquisa acadêmica brasileira, com a publicação do estudo: Cartografias Sentimentais (1989), na qual constrói um mapa acerca dos processos de subjetivações femininas e, assim, das possíveis modificações da identidade das mulheres durante o período que abrange 1950 e 1980. É o primeiro trabalho a utilizar a cartografia como metodologia experimental, guiando as análises psicológicas atreladas a contextos sociais. De acordo com a professora Rolnik, a “[...] prática do cartógrafo diz respeito, fundamentalmente, às estratégias de formação do desejo no campo social" (ROLNIK, 2011, p. 65).

A partir dessa amizade estabelecida com Suely, ${ }^{18}$ Guattari visitou o Brasil mais de seis vezes, entre os anos de 1982 1986, chegando até a conjecturar a possibilidade de se estabelecer no Brasil. Guattari, militante, fazia questão de se encontrar com os membros das mais diversas instituições sociais, em especial, mas não exclusivamente, com os militantes das minorias historicamente excluidas (movimentos de homossexuais, de feministas, de professores, de sindicalistas), além dos membros das

\footnotetext{
${ }^{14}$ No livro O anti-Édipo é a ideia de introduzir o desejo na produção e a produção no desejo. Um livro anti-materialismo histórico, nele, extraise o conceito de desejo de Freud e o de produção de Marx. Trabalham com o conceito de produção mas não restrita à geração de bens materiais ligada à força de trabalho, à infra-estrutura dos modos de produção, mas à produção em todos os domínios da realidade.

15 As datas das publicações correspondem aos anos em que essas obras foram publicadas na França.

${ }^{16}$ Durante a ditadura, Suely Rolnik é presa por fazer parte do movimento de contracultura. Exila-se em Paris, onde dá seguimento a seus estudos. Foi aluna de Deleuze, paciente e amiga de Guattari. Frequentadora da Clínica La Borde.

17 O livro foi publicado em 1986, mas a edição que seguimos é de 2013 (GUATTARI, Félix, ROLNIK, Suely. Micropolítica: cartografias do desejo. Rio de Janeiro: Editora Vozes. 2013. 340p.).

${ }^{18}$ Apesar da parceria com Félix Guattari, Rolnik é muito influenciada por Gilles Deleuze, foi sua aluna e amiga. Deleuze apresenta Suely a Guattari.
} 
associações de psicólogos e psicanalistas, universidades, partidos políticos etc. Em um desses encontros, entrevistou o então líder Sindical Luiz Inácio ${ }^{19}$ Lula da Silva ${ }^{20}$. A partir das décadas seguintes, em especial a partir de 1990, começamos a vislumbrar os primeiros ensaios da perspectiva da multiplicidade no campo acadêmico do Brasil, o que coincide com a primeira tradução em português do livro Mil Platôs $^{21}$. Em 1993, Rolnik, que encabeçava o núcleo de pesquisa em Subjetividade da PUC de São Paulo, criou, em conjunto com o grupo, o Caderno de Subjetividade, e nele, dá visibilidade a uma série de artigos e publicações homenageando o então recém-falecido Félix Guattari.

Para fins de contextualização, de historicidade da perspectiva no Brasil, precisamos destacar a importância de alguns autores brasileiros, que foram publicados nesta mesma revista. Entre eles, estão Peter Pál Pelbart (1993) e Luiz Orlandi (1996). Os dois estudiosos, além de Roberto Machado e Suely Rolnik, são os principais tradutores da obra de Deleuze e Guattari no Brasil.

Esse periódico, sozinho, foi o responsável pela publicação de uma parte considerável das pesquisas brasileiras influenciadas pela filosofia da diferença. Cada um dos autores acima citados, contamina e é contaminado de maneira diferente. Roberto Machado pesquisou a filosofia de Nietzsche por muitos anos e fez a transição através dos estudos do pensamento de Gilles Deleuze e seu lugar na história da filosofia. Isso o levou a publicar Deleuze e a filosofia, em 1990.

Em 2009, uma versão ampliada dessa mesma publicação é disponibilizada, sob o título Deleuze, a arte e a filosofia, que trata da influência do pensamento trágico de Nietzsche, que se dispõe a fazer a análise da relação entre arte e filosofia na trajetória de Gilles Deleuze.

Peter Pál Pelbart, por sua vez, teve a oportunidade de assistir às aulas de Deleuze. O assunto que o movimentava era o tempo, assunto que foi pesquisado, foi discutido e debatido em duas obras de igual importância: Nau do tempo-rei (1993) e $O$ tempo não reconciliado (1999).

O professor Luiz Orlandi é um dos grandes intérpretes do pensamento de Deleuze e Guattari no Brasil. Traduziu Diferença e repetição (com Roberto Machado, em 1988), A dobra (1991), Bergsonismo (1999), Empirismo e subjetividade (2001), A ilha deserta e outros textos (coordenador da tradução coletiva, em 2006), além de O anti-Édipo, de Deleuze e Guattari (2010), todos publicados pela Editora 34²2. Luiz Orlandi também atuou como coordenador de GT (grupos de tradução) ou revisor

\footnotetext{
${ }^{19}$ Luiz Inácio Lula da Silva, que mais tarde se tornou presidente do país, cargo que ocupou por dois mandatos consecutivos, elegendo a sucessora, a primeira mulher da história do país a ser eleita presidenta, Dilma Rousseff, que também ocupou o cargo por dois mandatos até sofrer o golpe em 2016.

${ }^{20}$ Entrevista realizada por Deleuze encontra-se em: https://tropicaline.files.wordpress.com/2012/04/lula-guattari1.pdf

${ }^{21}$ A publicação de Mil Platôs não foi a primeira tradução de uma obra de Deleuze e de Guattari no Brasil. A editora Imago já havia publicado Anti-Édipo, primeiro tomo de Capitalismo e Esquizofrenia, em 1976 e, em 1977, publica a obra Kafka, para uma literatura menor (apresentam erros na tradução). Em 1986, Suely Rolnik e Félix Guattari publicam Micropolíticas, cartografias do desejo (escrito em português). Roberto Machado traduz Diferença e Repetição em 1988. Em 1989 Sueli Rolnik publica a primeira edição de Cartografia Sentimental. Em 1992, somente um ano após a publicação do original, Bento Prado Jr. e Alberto Alonso Muñoz traduzem em parceria a obra: O que é filosofia? (Editora 34). Esse livro marca o começo de uma longa empreitada da Editora 34 na tradução e publicação das principais obras de Gilles Deleuze e Félix Guattari. Ao longo da segunda metade da década de 1990, a editora publicou as obras Mil Platôs: Capitalismo e Esquizofrenia, dividida em cinco volumes; e, em 2011, publica a segunda tradução brasileira do Anti-édipo. A editora portuguesa Assírio \& Alvim também já havia traduzido a obra em 1996.
}

22 No Brasil, a coleção TRANS, publicada pela Editora 34, foi uma das grandes responsáveis pela disseminação dessa perspectiva filosófica. Éric Alliez, ex-aluno de Deleuze, por muito tempo foi quem dirigiu a coleção. Publicou, também, textos de Bruno Latour, Michael Hardt, Toni Negri, Pierre Lévy, dentre outros, que ampliaram o que pensar com Deleuze \& Guattari. TRANS quer dizer transversalidade das ciências exatas e anexas, humanas e não humanas, transdisciplinaridade dos problemas. Em suma, transformação numa prática cujo primeiro conteúdo é que há linguagem e que a linguagem nos conduz a dimensões heterogêneas que não têm nada em comum com o processo da metáfora. (...) Sob a responsabilidade científica do Colégio Internacional de Estudos Filosóficos Transdisciplinares, a coleção TRANS propiciou ao público brasileiro inúmeras obras e suas traduções, incluindo textos inéditos. 
de traduções dos trabalhos de Deleuze e Guattari por anos e, assim, da perspectiva da filosofia da diferença para a referida editora, compondo uma produção de mais de 13 trabalhos, de autoria, revisão e coordenação de grupos de tradução.

\section{Os marginais da Diferença no campo da Educação e do Currículo}

Toda essa efervescência e movimentação acadêmica, vivenciada a partir dos anos 90 nas revistas e publicações, acaba por imiscuir-se em campos pedagógicos. Essas primeiras incursões da filosofia da diferença no território da pedagogia resultam em diferentes textos publicados, nos Cadernos de Subjetividade, entre eles, citamos o texto (1) Do paradigma Científico ao Paradigma Etico-Estetico e Político: Arte como Perspectiva nas Relações Educacionais. Foi escrito por Marisa Lopes da Rocha, Doutora em Psicologia Social e pesquisadora do Núcleo de Estudos e Pesquisas de Subjetividade da PUC-SP - dirigido por Rolnik -, em 1993 (Cadernos de Subjetividade, vol 1, número 2, Edição especial: Linguagens).

Esse texto é uma das primeiras incursões desse pensamento nos trabalhos acadêmicos voltados à pedagogia e à educação e que acaba por, ao mesmo tempo, inaugurar a filosofia da multiplicidade no campo teórico da educação, cujas referências são, respectivamente, Suely Rolnik e Félix Guattari, através dos livros: As três ecologias, de Guattari; e $O$ que é filosofia? de autoria de Deleuze \& Guattari.

No artigo, 'Do paradigma Cientifico ao Paradigma Etico-Estetico e Político: Arte como Perspectiva nas Relações Educacionais"'(Cadernos de Subjetividade, vol 1, número 2, Edição especial: Linguagens), Marisa Lopes da Rocha defende que a relação entre os docentes e os sujeitos deve ser compreendida enquanto construção coletiva, como uma obra de arte. Ainda segundo a autora, tanto docentes quanto sujeitos são parceiros de construção dessa obra de arte, que nada mais é do que a construção do conhecimento.

\section{Os primeiros artigos....}

A partir das primeiras publicações na revista Cadernos de Subjetividades, outros periódicos e pesquisadores começam a enveredar-se pelas linhas da diferença. Dentre os trabalhos contaminados, podemos citar de maneira muito conscisa, por questao de espaço e tempo,somente alguns poucos exemplos: o artigo Construtivismo pedagógico como significado transcendental do currículo, publicado em 1994, pela professora Sandra Corazza, inspirado em Derrida, é um importante marco na emergência dos estudos pós-críticos no Brasil; (1) O capricho das disciplinas (1994), (2) Foucault e Educação: outros estudos foucaultianos, de Alfredo Veiga-Neto, texto publicado em uma coletânea expressiva do pensamento filosófico educacional baseado em Foucault, $O$ sujeito da educação, organizada por Tomaz Tadeu da Silva, em 1994. (3) A análise do discurso: Para Além das palavras e das coisas (1995), de autoria da professora Rosa Maria Bueno Fischer, da Universidade Federal do Rio Grande do Sul, orientadora no Programa de Pos-Graduacão em Educação da UFRGS, publicados pela revista Educação \& Realidade em 1995. Em ambos os artigos A análise do discurso: Para Além das palavras e das coisas, Deleuze aparece na posição de comentador de Foucault, autor já conhecido e bem aceito no campo da pesquisa educacional e curricular. (4) $O s$ limites de uma pedagogia autogestionária: a experiência da pedagogia institucional, escrito pelo professor Sílvio Gallo (1999), e publicado na revista Pro-Posições, que cita somente a obra Revolução Molecular de Félix Guattari.

A partir dos anos 2000, o plano de emergência do pensamento deleuzeano- guattariano na cena apresenta-se com maior maturidade no campo curricular brasileiro - da Filosofia da Educação, no conjunto de três publicações: Dossiê Gilles Deleuze (2002); ainda em 2002, Esquizoanálise do Currículo, de Clermont Gauthier, no qual o autor desloca para o campo curricular conceitos da filosofica da diferenca, tais como: Rizoma, Esquizoanálize, Agenciamento, Desterritorialização, Máquinas.

Deleuze e a Educação (2003), Dossiê Entre Deleuze e a Educação (2005): O dossiê foi organizado pela professora Sandra Mara Corazza e pelo professor Tomaz Tadeu da Silva, que o fizeram como um número especial da Revista Educação \& 
Realidade, ligada à Faculdade de Educação da UFGRS. O número especial é composto de múltiplos e diferentes textos, pelos mais diversos tipos e estilos de escritas, de pessoas de diferentes áreas do conhecimento.

Precisamos lançar o olhar sobre os coloaboradores da Revista Educação e Realidade, pois são importantes nomes dentro da prespectiva da diferenca no campo curricular, que colaboraram com o texto, tais como: Tomaz Tadeu - com o artigo A arte do encontro e da composição: Spinoza + Currículo + Deleuze; Walter Kohan - com o escrito Entre Deleuze e a Educação: notas para uma política do pensamento; além da participação do professor Silvio Gallo - com o texto Em torno de uma educação menor.

A partir desse período, algumas revistas acadêmicas, da área da Educação/Ensino, dedicam edições especiais inteiras sobre pelo menos um dos autores da perspectiva do pensamento da filosofia da diferença, como: Educação \& Realidade (UFRGS, 2002, n. 27, v. 2), Educação e Sociedade (UNICAMP, 2005, n. 93,v. 26), Educação e Temática Digital (UNICAMP, 2012, vol. 14, n. 1), essa última tendo publicado um dossiê temático sobre Diferença e Subjetividade. Os autores que mais influenciaram essa publicação foram, respectivamente, Deleuze, Guattari e Foucault.

\section{E textos tornam-se livros ...}

Em 1994, os textos deixaram de aparecer somente nas revistas, tornaram-se livros com a publicação de: (1) Teorias educacionais críticas em tempos pós-modernos, organizado pelo professor Tomaz Tadeu da Silva. A professora Paraíso (2004) identifica-o como um marco para a filosofia pós-crítica e sua influência no pensamento educacional brasileiro. O livro foi escrito na forma de oito ensaios que foram os responsáveis pela produção de um mapa com as diferentes formas pelas quais o questionamento pós-moderno e pós-estrutural estava afetando o pensamento crítico em educação" (Paraíso, 2004, p. 285).

A partir desses primeiros movimentos, começamos a encontrar conceitos caros a estes pensadores, formulados ou não em parceria, e que têm aparecido de forma recorrente na literatura pedagógica: rizoma, devir, cartografia etc. Entretanto, foi somente a partir do início dos anos 2000, que essa perspectiva ganhou espaço dentro do campo da educação e se espalhou rizomaticamente, atingindo o sub-campo da pesquisa curricular, ocasião na qual esses trabalhos inspirados na Filosofia da Diferença começaram a ser discutidos em reuniões da ANPED.

\section{A diferença contamina o campo curricular}

É tambem em 2000 que a professora Sandra Mara Coraza aprensenta na ANPED um texto que foi publicado em 2001 e que discute o desgaste da proposta da teórico-critica de currículo - cujo título é Currículos alternativos/oficiais: o(s) risco(s) do hibridismo, na Revista Brasileira de Educação. Além disso, foi em 2001 que o professor Tomaz Tadeu da Silva publicou o livro: (2) Documentos de Identidade: uma introdução às teorias do currículo, pela Editora Autêntica.

Dentre os livros publicados a partir dessa perspectiva teórica e que contribuem para a permanência da perspectiva no campo curricular estão: (3) O que quer um Currículo - livro que marca a transição do pós-estruturalismo e dos estudos culturais para os estudos pós-críticos de currículo (2001).

Em 2002, tivemos uma forte presença das publicações do campo do currículo sob a contaminação da prespectiva da diferenca, entre elas: (4) Para uma filosofia do inferno em Educação, de autoria da professora Sandra Mara Corazza (2002); (5) O Oco do Vento: metodologia da pesquisa sociopoética e estudos transculturais, de autoria de Jacques Gauthier; (6) Metodologias de Pesquisa Pós-críticas em Educação, organizado por Dagmar Estermann Meyer e Marlucy Alves Paraíso; (7) Pesquisar na Diferença: um abecedário, organização de Tania Mara Galli Fonseca, Maria Lívia do Nascimento e Cleci Maraschin; (8) Filosofia: entre o ensino e a pesquisa, organizado por Carmelita Brito de Freitas Felício; (9) Pistas do Método da Cartografia: pesquisa-intervenção e produção de subjetividade, organizado por Eduardo Passos, Virgínia Kastrup e Liliana 
da Escóssia; e (10) Conexões: Deleuze e arte e ciência e acontecimento, organizado por Susana Oliveira Dias, Davina Marques e Antônio Carlos Amorim; do professor Tomaz Tadeu da Silva, alem do livro (11) Deleuze e a Educação (Gallo, 2003).

De 2004 até 2006, experienciamos um vácuo na produção. Contudo, encontramos o artigo da professora Paraíso, publicado em (2004) e intitulado 'Pesquisas pós-críticas em educação no Brasil: esboço de um mapa", no qual ela oferece uma ideia bastante consistente do início da intercessão Foucault/Deleuze e educação. Os textos referenciados pela professora Paraiso são: Sociologia da educação e pedagogia crítica em tempos pós-modernos, texto apresentado pelo professor Tomaz Tadeu da Silva e que se baseia em Deleuze; Poder e conhecimento: a constituição do saber pedagógico, apresentado por Lucíola Licínio de C. P. Santos, que fazia a utilização de Foucault como referencial teórico. (11) Currículo Documentos de Identidade (2008) e (12) Currículo como Fetiche (2009); (13) O Abecedário: Educação da Diferença publicados pela Professora Sandra Mara Corazza e Julio Groppo Aquino (2009), além de (14) Procedimento Erótico, Na Formação, Ensino, Currículo, de Gabriel Sausen Feil (2011); (15) Cadernos de notas 1:23 projeto, notas \& ressonâncias: um modo de ler-escrever em meio à vida. Coleção Escrileituras. Cuiabá: EdUFMT, (16) Didaticário De Criação: Aula Cheia, trabalho organizado da professora Sandra Mara Corazza (2012); (17) Deleuze e currículo no intervalo de palavras e imagens. In: Ferraço, C. E.; Gabriel, C. T.; Amorim, A. C. R. (Org.). Teóricos e o campo do currículo. Campinas, SP: FE/Unicamp (E-book GT Currículo) (2012); (18) Pedagogia das Máscaras aprender com o trágico de Deniz Alcione Nicolay (2012); (19) O Que Se Transcria Em Educação (2013); Caderno de Notas 5: arte, educação, filosofia. Oficinas produzidas em 2011. Coleção Escrileituras. Pelotas: Ed. UFPel., 2013; Cadernos de notas 6: experimentações de escrita, leitura e imagem na escola. Coleção Escrileituras. Porto Alegre: UFRGS/Doisa, 2014 (20) Entre a Educação e o plano de pensamento de Deleuze \& Guattari: uma Vida, Tese de doutorado que virou o livro de Cristiane Marinho (2014) : Filosofia e Educação no Brasil: dá identidade à diferença; (21) O Breviário dos Sonhos (2019) organizado pela professora Sandra Mara Corazza e grupo de Pesquisa Escrileituras da Diferença; Currículo e Didática da Tradução (PPGEDU/UFRGS). (22) Métodos de transcriação: pesquisa em educação da diferença, I - A Prolusão Metodosofia: Contrato De Tradução da Professora Sandra Mara Corazza publicado pela Editora OIKOS (2020).

Das obras acima mencionadas, somente duas não estão diretamente ligadas a grupos de pesquisa: Pistas do Método da Cartografia, resultado de um seminário realizado por dois anos na Universidade do Espírito Santo; e O Oco do Vento, escrita pelo criador do método da sociopoética, metodologia que conta com uma seara de adeptos na área educacional.

Os grupos de pesquisa que estabelecem ligação com as obras anteriormente citadas sao: Laboratório de Estudos Audiovisuais - OLHO, do qual faz parte o Professor Antonio Carlos Amorim, que trabalha com a perspectiva da Filosofia da Diferenca, no curriculo, através das artes; (FE- UNICAMP); Diferenças e Subjetividades em Educação - Dis (FE-UNICAMP); MultiTÃO: Liderador pela professora Susana Dias, prolifer-arte sub-vertendo ciências e educações (Labjor-UNICAMP); Kalos - Núcleo de Estudos e Pesquisa sobre o Ensino da Filosofia (UFG); PIVETES - Programa de Intervenção Voltadas às Engrenagens e Territórios de Exclusão Social (UFRGS); GECC - Grupo de Estudos e Pesquisa sobre Currículos e Culturas (UFMG); Geerge - Grupo de Pesquisa em Educação e Relações de Gênero (UFMG). Grupo de Pesquisa Escrileituras da Diferença; Currículo e Didática da Tradução (PPGEDU/UFRGS) que é composto por quatro núcleos universitários:

\footnotetext{
23 Cadernos de notas organizados por Corazza e parte do grupo de Pesquisa Escritu-Leituras: (1) Cadernos de notas 1: projeto, notas e ressonâncias: um modo de ler-escrever em meio à vida. Coleção Escrileituras. Cuiabá: EdUFMT, 2011; (2) Cadernos de notas 2: rastros de escrituras. Anais do I Colóquio Nacional Pensamento da Diferença Escrileituras em meio à vida (Canela/RS, 3,4 e 5 nov. 2011). Coleção Escrileituras. Canela: UFRGS, 2011; (3) Caderno de Notas 3: Didaticário de criação: aula cheia. Coleção Escrileituras. Porto Alegre: UFRGS, 2012. (4) Caderno de Notas 4: Pedagogia da tradução: entre bio-oficinas de filosofia. Coleção Escrileituras. 2012. (5) Caderno de Notas 5: arte, educação, filosofia. Oficinas produzidas em 2011. Coleção Escrileituras. Pelotas: Ed. UFPel., 2013. (6) Cadernos de notas 6: Experimentações de escrita, leitura e imagem na escola. Coleção Escrileituras. Porto Alegre: UFRGS/Doisa, 2014, (7) Caderno de notas 7: Biografemática na Educação: vidarbos. Coleção Escrileituras.. Porto Alegre: UFRGS/Doisa, 2015, (8) Cadernos de notas 8: Ética e Filosofia Política em meio à diferença e às Escrileituras. Coleção Escrileituras. Cascavel: EDUNIOESTE, 2016. (9) Caderno de Notas 9: Panorama de pesquisa em escrileituras: Observatório da Educação. Coleção Escrileituras. Porto Alegre: UFRGS/ Doisa, 2016. (10) Caderno de Notas 10: Traduções do Arquivo Escrileituras. Coleção Escrileituras. Porto Alegre: UFRGS/ Doisa, 2018.
} 
Universidade Federal do Rio Grande do Sul (UFRGS)/ Coordenação, Universidade Federal de Pelotas (UFPel), Universidade Federal do Mato Grosso (UFMT) e Universidade do Oeste do Paraná (UNIOESTE), um modo de ler-escrever em meio à vida, coordenado pela professora Corazza.

\section{Considerações não finais ...}

Tínhamos como objetivo principal identificar a maneira como a perspectiva da diferença, que é epistemológica, linguística, sem, contudo, deixar de ser política, contaminou as pesquisas curriculares brasileiras. Ao analisar o texto, fica claro que ela se estabeleceu através de um poderoso intercessor, o da amizade: estabeleceram-se vínculos e alianças entre os seres humanos, fluxos de vontade de transformar a si, de viver através desta linha não engessada que a arte permite acompanhar e criar "Se, para Deleuze, a arte é criação de afetos e perceptos, então ela também é uma massa de sensações que se sustenta por si, que possui consistência própria, por si é uma prática de experimentação" ( Ernst, Nicolay, 2021).

Pelo viés epistemológico os trabalhos acima mencionados fazem parte de um posicionamento de testemunho dessas contribuições ao campo da educação, ensino e currículo para o diferente e a diferença. A partir da linguagem torna-se " um dispositivo saber-poder-verdade de linguagem." (Corazza, 2001, p.10), sendo a verdade entendida, a partir de Nietzsche e de Deleuze, como uma interpretação resultante de diferentes pontos de vista, sendo ela a interpretação invenção que possibilita a criação de novos significados, ou seja, conhecer não é descobrir, não é adequar "é atribuir sentido, dar peso, valorar" (Silva, 2001).

Pelo viés político, permite aos pesquisadores assumirem o currículo como campo dos primados dos desejos e dos significados, currículo é um Corpo sem Órgaos CSO, um território, uma prática cultural essa sempre relacionada socialmente, não podendo ser pensada fora das relações de poder, é também conexão, é fetiche em seu papel constitutivo e não determinado. Ou seja, o currículo a partir da diferença segue linha contrária de uma única narrativa, de uma única epistemologia, por permitir questionar esse caráter universalizante, entendendo que as multiplicidades autorizaram docentes e pesquisadores questionarem o historicamente estabelecido, "os escritos que contaram com a participação de Deleuze e Guattari podem ser resumidamente pensados como variado lugar de encontros, como movediço lugar de articulações" (Orlandi, 2000, P. 49).

Esses lugares, esses acessos sempre atrelados a estratos (estratificações, que se organizam através de camadas e podem ser identificadas enquanto: saberes, disciplina, livros didáticos, textos, projetos, habilidades e competências). Pensar currículos a partir da diferença torna-se um fluxo desconfortante, que movimenta, que promove o caos dentro do caos que vivemos, compreendendo os diferentes contextos humanos, atrelados aos contextos: social, cultural, tecnológico, de resistência ao sistema, servem como fundamento para essa filosofia que coloca voz e lugar de fala aos que há anos foram silenciados por outros pensadores. Resistir a tudo aquilo que nos sufoca, que diminui a potência do nosso pensar, e de traçar linhas de fuga.

Dessa maneira, precisamos lembrar que são nesses traçados onde as trocas e o caos se estabelecem, ou seja, "possibilidade de uma dialética do desejo, de uma imprevisão do desfrute: que os dados não estejam lançados, que haja um jogo" (Barthes, 1987, P. 9).

Essa pesquisa não deixa de ressonar e assim fluir através desses entendimentos, de que o retribuir se faz através do movimento de preservar os encontros e, assim, propiciar a outros, novos encontros a partir destes.

\section{Agradecimentos}

As mulheres e homens que participaram direta ou indiretamente da contaminação da diferença e ousaram pensar para além do estabelecido. cada um em seu espaço-tempo, em seu campo de pesquisa e atuação, possibilitaram transformar a educação 
e a pesquisa com seus ditos e escritos, inspirando outros a viverem, pesquisarem e escreverem pela e com a diferença. Em especial a professora Sandra Mara Corazza.

\section{Referências}

Alliez, E.(1996). Deleuze no Brasil. In: Cadernos de subjetividade. Núcleo de Estudos e Pesquisa da Subjetividade do Programa de Estudos Pós-Graduados em Psicologia Clínica da PUC-SP. Num. Esp.

Barthes, R.(2012). O rumor da língua. Tradução Mário Laranjeira. (3ª. ed.): Martins Fontes

Amorim, A. C. R. (2012). Deleuze e currículo no intervalo de palavras e imagens. In: Ferraço, C. E., Gabriel, C. T., \& Amorim, A. C. R. (Org.). Teóricos e o campo do currículo: FE/Unicamp (E-book GT Currículo).

Amorim, A. C. R. (2013). Três crianças a compor um plano para o currículo. Currículo sem fronteiras, Rio de Janeiro, 13(3), 411-426. http://www.curriculosemfronteiras.org/v.13iss3articles/amorim.pdf.

Barone, E. (2013).A Moving Outward Into Communion With Others, p. 64.

Burke, P. (1992). O mundo como teatro - estudos de antropologia histórica.: Difel.

Craia, E. C. P.(2005) Deleuze e a ontologia: o ser e a diferença. IN: Orlandi, Luiz B. L. (Org.). A diferença: Editora da UNICAMP, 2005.

Corazza, S. M. (2001). Currículos alternativos/oficiais: o(s) risco(s) do hibridismo. Revista Brasileira de Educação, (17), 100-114. https://dx.doi.org/10.1590/S1413-24782001000200008

Corazza, S. M. (2001) O que quer um currículo? Pesquisas pós-críticas em educação. Petrópolis, Vozes.

Corazza, S. (2001). Currículos alternativos/oficiais: o(s) risco(s) do hibridismo. Revista Brasileira de Educação. S/v, n.17, $100-114$.

Corazza, S. M., \& Silva, T. T. (Orgs).(2002). Dossiê Gilles Deleuze. In: Educação \& Realidade. Porto Alegre, 27(2). https://seer.ufrgs.br/educacaoerealidade/issue/view/1574

Corazza, S. M. (2002). Noologia do currículo: Vagamundo, o problemático, e Assentado, o resolvido. Educação \& Realidade, Porto Alegre, 27(2), 131-142. https://seer.ufrgs.br/educacaoerealidade/article/view/25923/15191

Corazza, S. M. (2006). Artistagens: filosofia da diferença e educação: Autêntica.

Corazza, S. M., Rodrigues, C., Heuser, E. M. D., \& Monteiro, S. B. (2014). Escrileituras: um modo de ler-escrever em meio à vida. Educação e Pesquisa, 40(4), 1029-1043. https://dx.doi.org/10.1590/S1517-97022014121435

Corazza, S. M. (2016). Currículo e Didática da Tradução: vontade, criação e crítica. Educação \& Realidade, 41(4), 1313-1335. Epub August 22, 2016.https://dx.doi.org/10.1590/2175-623658199

Deleuze, G. (1988). Diferença e repetição. Tradução Luiz Orlandi, Roberto Machado. Rio de Janeiro: Graal.

Deleuze, G. (1999). Bergsonismo. Tr. Luiz Orlandi. São Paulo: Ed. 34.

Deleuze, G., \& Parnet, C.(2004). Diálogos. Tradução de José Gabriel Cunha.: Relógio D’água Editores.

Deleuze, G., \& Parnet, C. (1994). O abecedário de Gilles Deleuze.

Deleuze, G. (1999).Nietzsche e a filosofia: Editora Rés, s/d.

Deleuze, G., \& Guattari, F. O que é filosofia?(1992). Tradução de Bento Prado Jr. E Alberto Alonso Muñoz. Ed. 34. (Coleção TRANS).

Deleuze, G. (1993). Até O Fim... In Cadernos De Subjetividade/Núcleo De Estudos E Pesquisas Da Subjetividade Do Programa De Estudos Pós-graduados Em Psicologia Clínica Da Puc-sp.Volume I, N 1, São Paulo. P. 57. https://revistas.pucsp.br/index.php/cadernossubjetividade/article/view/38106/25849

Deleuze, G., \& Parnet, C. (2004).Diálogos. Tradução: José Gabriel Cunha: Relógio D’água Editores.

Deleuze, G. (1992). Conversações. Tradução: Peter Paul Pelbart. Editora 34.

Deleuze, G.(2010). Proust E Os Signos.. Tradução: Antonio Piquet; Roberto Machado. Forense Universitária.

Deleuze, G. (2013). A Imagem Tempo. Tradução: Heloisa A. Ribeiro: Brasiliense.

Deleuze, G., \& Guattari, F.(1994). O Que É Filosofia. Tradução: Bento Prado Jr. Alberto Muñoz: Editora 34.

Deleuze, G., \& Guattari, F. (1995). Mil Platôs. Capitalismo e esquizofrenia. v.1.Tradução: Aurélio Guerra Neto; Célia Costa: Editora 34.

Derrida, J. (1995) - "Freud E A Cena Da Escritura" In "A Escritura E A Diferença" - P. 179-227 - Editora Perspectiva - (2ª Edição).

Derrida, J. (2001) - "Mal De Arquivo - Uma Impressão Freudiana" - Editora Relume Dumará - Rio De Janeiro. 
Dosse, F. (2010). Gilles Deleuze \& Félix Guattari. Biografia cruzada: Artmed.

Ernst, D. C., \& Nicolay, D. A. (2020). Cartografias da diferença na pesquisa curricular do ensino de Ciências da Natureza e Matemática.Research, Society and Development, 9(11), e96591110246. https://doi.org/10.33448/rsd-v9i11.10246

Fischer, R. M. B. (1994). O Capricho Das Disciplinas. Educação E Realidade, Porto Alegre, Universidade Federal Do Rio Grande Do Sul, 19(2), 47-66. https://seer.ufrgs.br/educacaoerealidade/issue/viewFile/3035/364

Fischer, R. M. B. (1995). A Análise Do Discurso: Para Além De Palavras E Coisas. Educ. Real, Porto Alegre, 20(2), p.18. https://seer.ufrgs.br/educacaoerealidade/article/view/71741

Fischer, R. M. B. (2002). Problematizações sobre o exercício de ver: mídia e pesquisa em educação. Revista Brasileira de Educação, (20), 83-94. https://dx.doi.org/10.1590/S1413-24782002000200007

Fischer, R. M. B. (2008). Mídia, Juventude e Memória Cultural. Educação \& Sociedade, Campinas, $29(104)$, 667 - 686. https://www.scielo.br/pdf/es/v29n104/a0329104.pdf

Foucault, M., \& Deleuze, G. (1984). Os intelectuais e o Poder (entrevista) in FOUCAULT, Michel. Microfísica do Poder: Ed. Graal. p. 69-78.

Gallo, S.(2000). O que é filosofia da educação? Anotações a partir de Deleuzee Guattari. Perspectiva, Florianópolis, 18(34), 49-68. https://periodicos.ufsc.br/index.php/perspectiva/article/view/10418

Gallo, S.(2002). Em torno de uma educação menor. Educação e Realidade, Porto Alegre, 27(2), 169-178: https://seer.ufrgs.br/educacaoerealidade/article/view/25926/15194

Gallo, S. Deleuze \& a Educação: Autêntica Editora, 2003.

Gallo, S. (2007). Currículo ( entre) imagens e saberes. Palestra proferida no V Congresso Internacional de Educação. São Leopoldo. Pedagogias (entre) lugares e saberes. http://www.grupodec.net.br/wp-content/uploads/2015/10/GalloEntreImagenseSaberes.pdf

Gallo, S. (2001). Conhecimento, transversalidade e currículo. In: Reunião anual da ANPED, 24. Programa e resumos. Associação Nacional de Pós-Graduação e Pesquisa em Educação,Caxambu, MG, 2001.

Gallo, S. Transversalidade e Meio Ambiente. Ciclo de Palestras sobre Meio Ambiente. Secretaria de Educação Fundamental. Brasília: MEC,SEF, 2001. https://download.inep.gov.br/download/cibec/pce/2001/15-26.pdf

Gallo, S. Currículo como máquina de subjetivação.In: Orgs: Ferraço, C. E. Carvalho, J. M. In: Currículos, Pesquisas, Conhecimentos e Produção de subjetividades. Vitória, ES: Nupec/UFes, p. 203- 218, 2013. http://repositorio.ufes.br/handle/10/1158

Gallo, S.(2002). Em torno de uma educação menor. In: Dossiê Gilles Deleuze. Educação e Realidade, Porto Alegre, 27(2), 169-178. https://seer.ufrgs.br/educacaoerealidade/article/view/25926

Gandin, L. A., Paraskeva, J. M., \& Hypolito, Á. M. (2002). Mapeando a (complexa) produção teórica educacional- Entrevista com Tomaz Tadeu da Silva. Currículo sem fronteiras, Rio de Janeiro, 2(1), 5-14. http://www.curriculosemfronteiras.org/vol2iss 1articles/tomaz.pdf.

Gauthier, C. (2002). Esquizoanálise do currículo. Educação \& Realidade, p. 143-155, 27(2), p.143-155. https://seer.ufrgs.br/educacaoerealidade/article/view/25924

Gil, J., Corazza, S. M., \& Tadeu, T.(2003). Ele foi capaz de introduzir no movimento dos conceitos o movimento da vida . Educação \& Realidade, Porto Alegre, 28(2), 205-224. https://seer.ufrgs.br/educacaoerealidade/article/view/31077

Guattari, F., \& Rolnik, S.(2005). Micropolítica, cartografias do desejo: Vozes, 2005.

Guattari, F. (1982). Guattari entrevista Lula: Brasiliense, 1982.

Guattari, F. (1993).Guattari na PUC. In Cadernos de Subjetividade/Núcleo de Estudos e Pesquisas da Subjetividade do Programa de Estudos Pós-Graduados em Psicologia Clínica da PUC- SP. Volume I, n 1, São Paulo, 1993a. p. 10-29.

Guattari, F.(1993). A paixão das máquinas. In Cadernos de Subjetividade/Núcleo de Estudos e Pesquisas da Subjetividade do Programa de Estudos PósGraduados em Psicologia Clínica da PUC-SP. Volume I, n ${ }^{\circ} \quad 1, \quad$ São Paulo, 1993 b. 40-51. https://revistas.pucsp.br/index.php/cadernossubjetividade/article/view/38765

Guattari, F. (2001). As três ecologias.. Tradução de Maria Cristina F. Bittencourt. (12 ${ }^{\mathrm{a}}$. ed.): Papirus Editora.

Guattari, F. (2008) A Filosofia é Fundamental à existência Humana.(2008). Grandes Entrevistas. Paris: TV Francesa, 1989-1990. Este conteúdo foi reproduzido no Brasil pela Fundação Universidade Federal do Rio Grande do Sul, em 2008. http://www.youtube.com/watch?v=Fk_OrkMG5YI

Kastrup, V., \& Barros, R. B. de.(2009). Movimentos-funções do dispositivo na prática da cartografia. In: Passos, E., Kastrup, V., Escóssia, L. da. org (s.). Pistas do método da cartografia: Pesquisa-intervenção e produção de subjetividade.: Sulina.p. 32- 51.

Kastrup, V.(2009). O funcionamento da atenção no trabalho de cartógrafo. In: Passos, Eduardo; Kastrup, Virgínia; Escóssia, Liliana Da Org (S.). (2009). Pistas do método da cartografia: Pesquisa-intervenção e produção de subjetividade.p. 32- 51: Sulina. 
Kohan, Walter, O.(2002). Entre Deleuze e a educação: notas para uma política do pensamento. In: Educação e Realidade, Porto Alegre, RS, 27(2), 123-130. www.4shared.com/office/.../Kohan_Walter_Omar_Entre_Deleuz.htm

Lacan, J.(1999).O Seminário, livro 5: as formações do inconsciente: Jorge Zahar. (Coleção Campo Freudiano no Brasil).

Lévy, P.(1993). As tecnologias da inteligência: Ed. 34.

Lopes, A. C., \& Macedo, E.(2002). O pensamento curricular no Brasil. Currículo: debates contemporâneos. São Paulo, Cortez.

Machado, R. (2009). Deleuze, a arte e a filosofia: Ed. Jorge Zahar.

Nora, P. (1993). Entre memória e história: a problemática dos lugares. Revista do Projeto História. São Paulo, n. 10, p. 7-28.

Nunes, C. (1990). História da educação: espaço do desejo. Em Aberto. Brasília, n. 47,p. 37-46.

Paraíso, M. A. (2004). Pesquisas pós-críticas em educação no Brasil: esboço de um mapa. In: Cadernos de Pesquisa, 34(122), 283-303. www.scielo.br/scielo.php?pid=S0100-15742004000200002.

Pereira, M. V. (2013). A escrita acadêmica: do excessivo ao razoável. Rev. Bras. Educ.Rio de Janeiro. http://www.scielo.br/scielo.php? script=sci_arttext\&pid=S1413-24782013000100013\&lng=pt\&nrm=iso $>$.

Pelbart, P. P. (1993). Um direito ao silêncio. Caderno de subjetividade, São Paulo, 1(1), 41-48.

Pelbart, P. P., \& Rolnik, S. (Orgs).(1996). Cadernos de Subjetividade. Número Especial Deleuze. Núcleo de Estudos e Pesquisa da Subjetividade. Programa de Estudos Pós-Graduados em Psicologia Clínica da PUC-SP. S.P. https://revistas.pucsp.br/index.php/cadernossubjetividade/issue/view/1962

Pelbart, P., P. Nau Do Tempo-rei: 7 Ensaios Sobre O Tempo Da Loucura: Imago Ed. 1993.

Pelbart, P. O Tempo Não-Reconcliliado. Imagens do Tempo em Deleuze. São Paulo, Perspectiva, 2004.

Ríos, G. (2002). A captura da diferença nos espaços escolares: um olhar deleuziano Educação \& Realidade, 27(2), 111-122. https://seer.ufrgs.br/educacaoerealidade/article/view/25921

Rigodanzo, S., Ernst, D. C., Keske, C., \& Nonenmacher, S., S. E. B. (2020). O currículo e o ensino de ciências da natureza - primado dos desejos e das subjetividades: uma discussão a partir da filosofia da diferença. XXI Encontro Nacional de Educação nas Ciências (ENACED) e I Seminário Internacional de Estudos e Pesquisa em Educação nas Ciências (SIEPEC). Unijuí. https://www.publicacoeseventos.unijui.edu.br/index.php/enacedesiepec/article/view/18704

Rocha, M. L Da. (1993). Do paradigma científico ao paradigma ético-estético e político: a arte como perspectiva nas soluções educacionais. São Paulo: Cadernos de subjetividade. 1(2), 217-234. Disponivel em: https://revistas.pucsp.br/index.php/cadernossubjetividade/article/view/38133/25869

Rolnik, S. (1989).Cartografia sentimental: transformações contemporâneas do desejo: Estação Liberdade.

Schérer, R. (2005).Aprender com Deleuze. IN: Dossiê 'Entre Deleuze e a educação'. In: Educação e Sociedade 26(93) . Set./Dez. CEDES; Campinas. Schöpke, R. (2004). Por uma filosofia da diferença: Gilles Deleuze, o pensador nômade: Contraponto; São Paulo: Edusp.

Silva, T. T. Da. (2002).Mapeando a [complexa] produção teórica educacional - Entrevista com Tomaz Tadeu da Silva. In: Currículo sem fronteiras, 2(1), 5-14, Jan/Jun., 2002. www.curriculosemfronteiras.org/vol2iss1articles/tomaz.pdf.

Silva, T. T. (2002). O Dr. Nietzsche, curriculista - com uma pequena ajuda do professor Deleuze. In: Antonio Flávio Barbosa Moreira; Elizabeth Fernandes de Macedo. (Org.). Currículo, práticas pedagógicas e ento identidades.: http://www.4shared.com/office/h5oVK2tN/Silva_Tomaz_Tadeu_Dr_Nietzsche.html

Silva, T. T., \& Kohan, W. O.(2005). (Orgs). Dossiê 'Entre Deleuze e a educação'. In: Educação e Sociedade 26(93). CEDES; Campinas. https://1library.org/document/qo5o4rmy-educ-soc-vol-numero.html

Silva, M. A. (2006). Currículo para além da pós-modernidade. In: Associação Nacional de Pós-graduação e Pesquisa em Educação Nacional - ANPED, 29o, Caxambu. http://www.fe.unicamp.br/gtcurriculoanped/29RA/trabalhos/silvaMA.pdf

Silva, R. M. D. da. (2014). Educação, cidadania e agenciamentos formativos nas políticas culturais brasileiras. Educação \& Sociedade, 35(127), 397-415. https://dx.doi.org/10.1590/S0101-73302014000200004

Silva, T. T. Da. (1999) Documentos De Identidade. Uma Introdução Às Teorias Do Currículo: Autêntica.

Silva, T. T. Dá. (2002). A arte do encontro e da composição: Spinza + currículo + Deleuze. Educação \& Realidade, Porto Alegre, 27(2), 31-45. https://seer.ufrgs.br/educacaoerealidade/article/view/25915/15184

Tadeu, T. Da. (2005). Deleuze e a questão da literalidade: uma via alternativa. Educação \& Sociedade, 26(93), 1331-1338. https://doi.org/10.1590/S010173302005000400014

Silva, T. T. da. (2007).Políptico. Educação em Revista, Belo Horizonte, n. 45, 309-322. https://www.scielo.br/pdf/edur/n45/a16n45.pdf Valéry, P. (2016). Maus pensamentos \& outros. Tradução de Pedro Sette-Câmara: Editora Âyiné.

Veiga-neto, A. (2011). Foucault e a Educação: Autêntica. 
Research, Society and Development, v. 10, n. 2, e52110211750, 2021 (CC BY 4.0) | ISSN 2525-3409 | DOI: http://dx.doi.org/10.33448/rsd-v10i2.11750

Zordan, P. (2005). Arte com Nietzsche e Deleuze. Educação \& Realidade, Porto Alegre, 30(2), 261-272. https://seer.ufrgs.br/educacaoerealidade/article/view/12472

Zordan, P. (2015). Movimentos e Matérias da Iniciação à Docência. Educação \& Realidade, 40(2), 525-547. Epub .https://doi.org/10.1590/2175-623645945 